\title{
PROBABLE INVERTED TANDEM DUPLICATION OF Xp IN A 46,Xp+Y BOY
}

\author{
Kouji Narahara, Yoshifumi Kodama, Shunsuke Kimura, \\ and Hiroshi Кімото \\ Department of Pediatrics, Okayama University School \\ of Medicine, Okayama 700, Japan
}

\begin{abstract}
Summary A mentally retarded 16-month-old boy with subnormal stature, strabismus, anteverted nares and deformed ears was found to have a de novo structural rearrangement of the $\mathrm{X}$ chromosome $(46, \mathrm{Xp}+\mathrm{Y})$. The banding patterns of the abnormal $X$ chromosome were interpreted to be an inverted tandem duplication of the segment Xp22.1 $\rightarrow X p 22.3$. Several other possibilities were considered but thought less likely. DNA replication studies with BrdU incorporation revealed the replication pattern of the duplicated segment to be similar to the equivalent portion of the $\mathrm{X}$ chromosome.
\end{abstract}

\section{INTRODUCTION}

Various structural rearrangements of the $\mathrm{X}$ chromosome have been described in a number of women with gonadal dysgenesis. They include isochromosomes for the long and short arms, deletions of the long and short arms, ring formations and pericentric inversions of the $X$ chromosome, and $X$-autosome, $X-X$ and $X-Y$ translocations. Structural aberrations of the $X$ chromosome in men, on the other hand, have been reported much less frequently. We would like to describe a boy with a de novo mirror duplication of the distal portion of $\mathrm{Xp}$, a hitherto unreported aberration.

\section{CASE REPORT}

The patient, a boy, was born at term on July 9, 1976 in the second uncomplicated pregnancy. His parents were unrelated. The first pregnancy had resulted in an early spontaneous abortion. No family history indicating congenital defects or mental retardation was present. The mother was 24 years old and the father 26 when the patient was born. The delivery was induced uneventfully. The birth weight was $3,100 \mathrm{~g}$. During the first 3 months of life, the infant was always a poor feeder and failed to thrive. Delayed development was noticed at 5 months of age. 


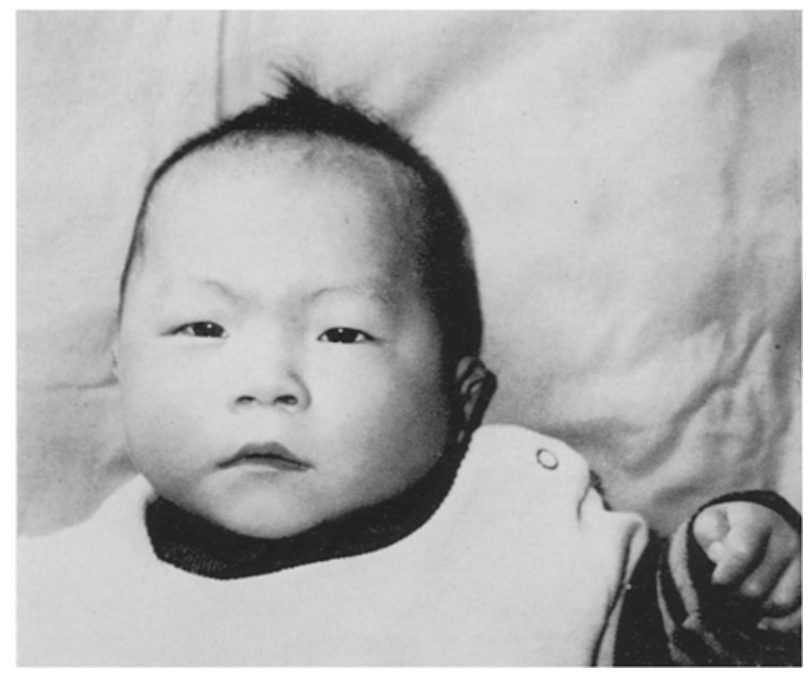

Fig. 1. The patient at 16 months of age. Note right internal strabismus, anteverted nares, and a carpshaped mouth.

Upon physical examination at 16 months of age, the body weight was 7,240 g, the height $72.3 \mathrm{~cm}$, and the head circumference $43.0 \mathrm{~cm}$; all the figures were less than the 3 rd percentile. He could not stand unsupported or say any meaningful words. He had anteverted nares, right internal strabismus, a carp-shaped mouth, and deformed ears with folded helix and prominent antihelix (Fig. 1). Otherwise, no major malformations were observed, including genital organs. Dermatoglyphic patterns of the patient consisted of 5 loops, 3 arches and 2 whorls on the fingertips, a total finger ridge count of 27 , a transitional simian crease on the right palm, and a radial loop pattern in the left thenar area.

\section{CYTOGENETIC FINDINGS}

Cytogenetic studies of the patient and his parents were performed using cultured peripheral blood lymphocytes. Conventional chromosome preparations from the patient revealed a $46, \mathrm{Xp}+\mathrm{Y}$ karyotype. Based on G-, R-, Q- and C-banding pattern of the early metaphases, the $X$ chromosome abnormality was interpreted as an inverted tandem duplication of region $\mathrm{Xp} 22.1 \rightarrow \mathrm{Xp} 22.3$ (Fig. 2). The karyotype was designated as $46, \mathrm{Y}$, inv dup $(\mathrm{X})(\mathrm{pter} \rightarrow \mathrm{p} 22.3: \mathrm{p} 22.1 \rightarrow \mathrm{p} 22.3: \mathrm{p} 22.3 \rightarrow \mathrm{qter}$ ).

DNA replication studies with BrdU incorporation and acridine orange staining (Dutrillaux et al., 1973) revealed a similarity between the replication pattern of the extra Xp segment and the equivalent portion of the X chromosome (Fig. 3). This indicates that the extra segment was early replicating and thus genetically active, 


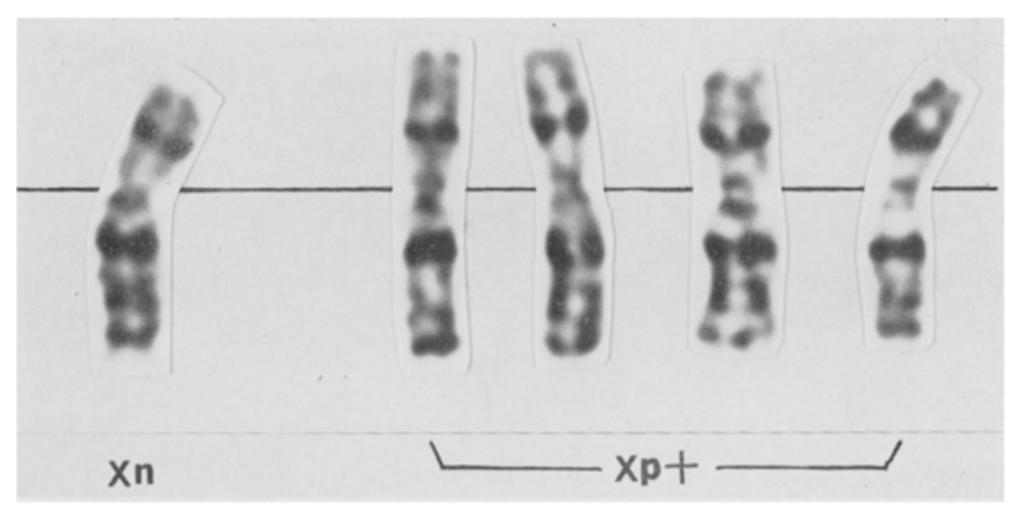

Fig. 2. G-banding patterns in normal $(\mathrm{Xn})$ and $\mathrm{ab}-$ normal $(\mathrm{Xp}+) \mathrm{X}$ chromosomes.

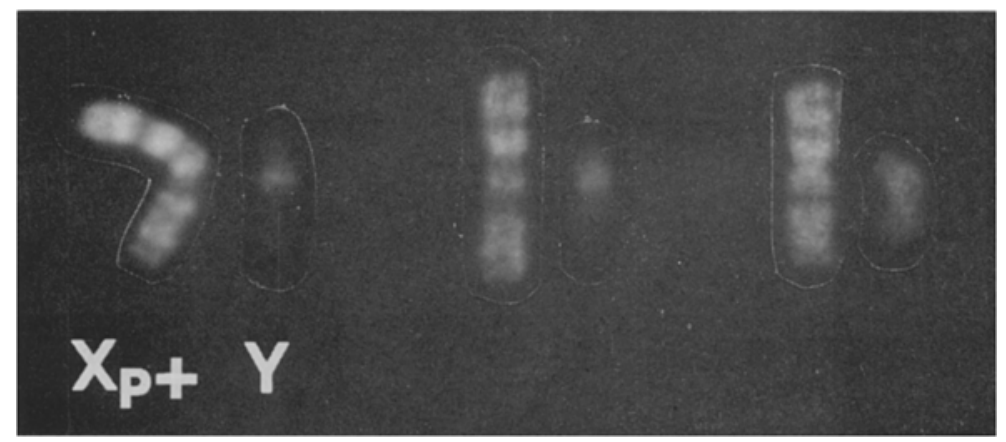

Fig. 3. DNA replication patterns in the $\mathrm{Xp}+$ and $\mathrm{Y}$ chromosomes. BrdU incorporation followed by acridine-orange staining.

and further supports the interpretation of inverted tandem duplication. The Xchromatin test in the buccal epithelial cells was negative. Both parents had normal G-banded chromosomes.

\section{DISCUSSION}

The $\mathrm{X}$ chromosome abnormality in our case was interpreted as inverted tandem duplication of the distal portion of Xp. Other interpretations, such as direct tandem duplication and $\mathrm{X}$-autosome or $\mathrm{X}-\mathrm{X}$ translocation, were possible but seemed less likely. The interpretation of inverted tandem duplication, however, is not conclusive in view of the paucity of bands in the chromosome segment involved and also due to the lack of supportive clinical evidence. Inverted tandem duplications have been previously described in various autosomes but not in the $\mathrm{X}$ chro- 


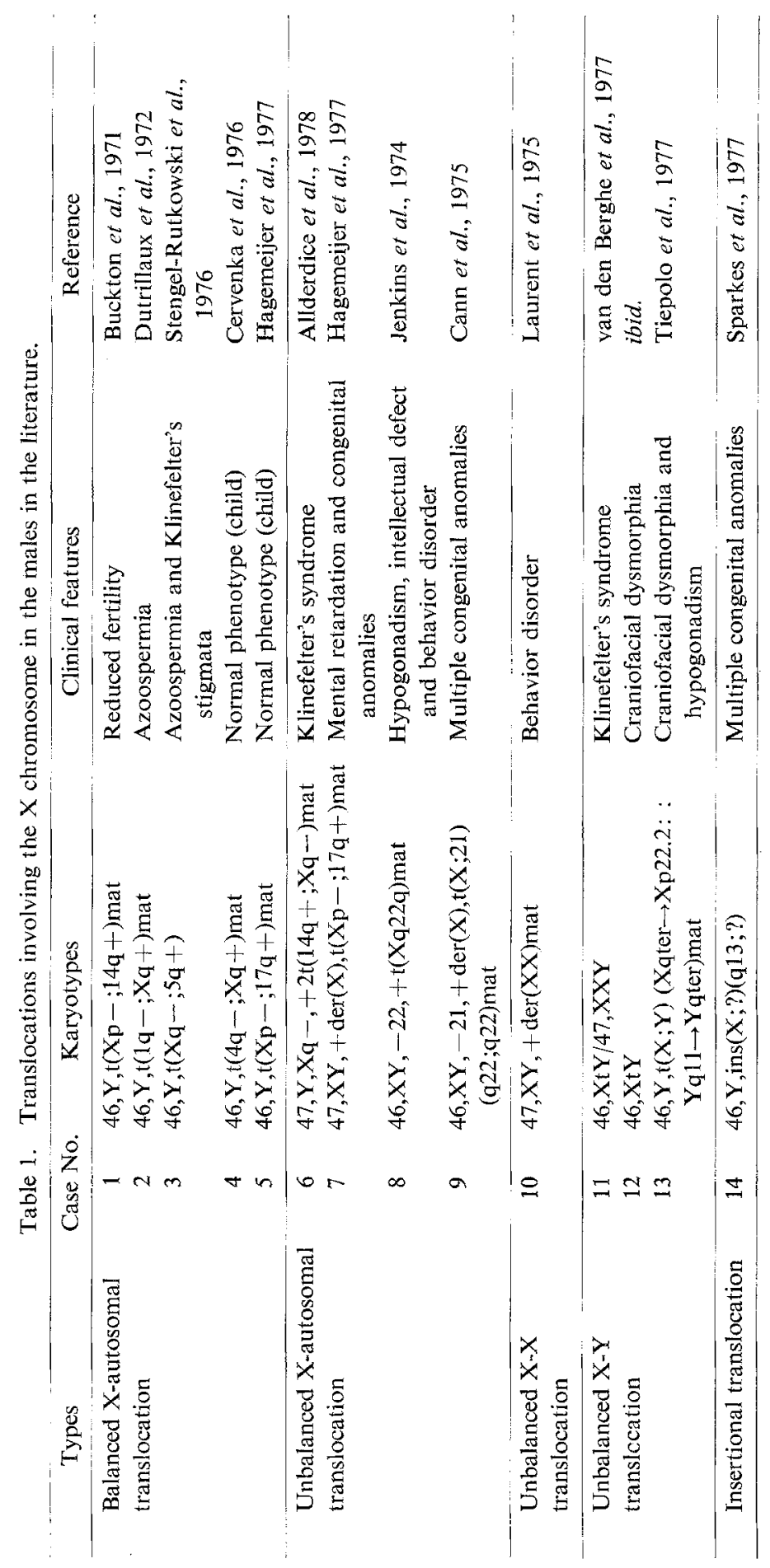


mosome ( $c f$. Taylor et al., 1977, for reference). All the inverted tandem duplication reported up to the present have been sporadic, a fact also in support of our interpretation.

Fourteen instances of structural aberrations of the $\mathrm{X}$ chromosome in males have been described in the literature. They can be classified into five groups: (1) balanced $\mathrm{X}$-autosome translocations (5 cases), (2) unbalanced X-autosome translocations (4 cases), (3) an unbalanced X-X translocation, (4) unbalanced X-Y translocations ( 3 cases), and (5) an insertional translocation of the $X$ chromosome (Table 1). It seems that the presence of the material from at least one entire $X$ chromosome, with the possible exception of the terminal portion of $\mathrm{Xp}$, is essential for survival. Cases 12 and 13 in Table 1 with an unbalanced X-Y translocation, in spite of nullisomy for the terminal segment of $\mathrm{Xp}$, were life sustaining and showed few physical abnormalities. This would indicate the localization of few vital genes in this segment. Case 14 had a small chromosome segment of unknown origin inserted into the long arm of the $\mathrm{X}$ chromosome. The banding patterns of the $\mathrm{X}$ chromosome are also consistent with the interpretation of direct duplication of the segment $\mathrm{Xq} 13 \rightarrow \mathrm{Xq} 24$. All the abnormalities, except in Case 14, were inherited.

BrdU-acridine-orange staining in our case provided evidence that the extra chromosome segment is early replicating and therefore genetically active. It is tempting to try to relate the activity of the duplicated $\mathrm{X}$ segment with the phenotype of the patient.

\section{REFERENCES}

Allderdice, P. W., Miller, O. J., Miller, D. A., and Klinger, H. P. 1978. Spreading of inactivation in an $(\mathrm{X} ; 14)$ translocation. Am. J. Med. Genet. 2: 233-240.

Berghe, H. van den, Petit, P., and Fryns, J. P. 1977. Y to X translocation in man. Human Genet. 36: 129-141.

Buckton, K. E., Jacobs, P. A., Rae, I. A., Newton, M. S., and Sanger, R. 1971. An inherited Xautosome translocation in man. Ann. Human Genet. 35: 171-178.

Cann, H. M., Sakaguchi, S., Stone, J., Gold, E., and Luzzatti, L. 1975. Familial X-autosome translocation (X;21). Am. J. Human Genet. 27: 23 (abstract).

Cervenka, J., Djavadi, G. R., and Gorlin, R. J. 1976. Partial trisomy 4q syndrome: Case report and review. Human Genet. 34: 1-7.

Dutrillaux, B., Couturier, J., Rotman, J., Salat, J., and Lejeune, J. 1972. Stérilité et translocation familiale t(1q-; Xq +). C.R. Acad. Sci. 274: 3324-3327.

Dutrillaux, B., Laurent, C., Couturier, J., and Lejeune, J. 1973. Coloration par l'acridine orange de chromosomes préalablement traités par le 5-bromodeoxyuridine (BUDR). C. R. Acad. Sci. 276: 3179-3181.

Hagemeijer, A., Hoovers, J., Smit, E. M. E., and Bootsma, D. 1977. Replication pattern of the X chromosomes in three X/autosomal translocations. Cytogenet. Cell Genet. 18: 333-348.

Jenkins, M. B., Davis, E., Thelen, T. H., and Boyd, L. 1974. A familial X-22 translocation with an extra X chromosome. Am. J. Human Genet. 26: 736-745.

Laurent, C., Biemont, M. C., and Dutrillaux, B. 1975. Sur quatre nouveaux cas de translocation du chromosome $\mathrm{X}$ chez l'homme. Humangenetik 26: 35-46. 
Sparkes, R. S., Salter, W. J., Blaker, R. G., and Muller, H. M. 1977. Insertional translocation into the X chromosome of a 46,XY male. Clin. Genet. 12: 114-118.

Stengel-Rutkowski, S., Zankl, H., Rodewald, A., Scharrer, S., Chaudhuri, J. P., and Zang, K. D. 1976. Aspermia, associated with a presumably balanced X/autosomal translocation; karyotype 46,Y,t(X; 5) (q28; q11). Human Genet. $21: 97-106$.

Taylor, K. M., Francke, U., Brown, M. G., George, D. L., and Kaufhold, M. 1977. Inverted tandem "mirror" duplication in human chromosomes: inv dup 8p, 4q and 22q. Am.J. Med. Genet. 1: 3-19.

Tiepolo, L., Zuffardi, O., and Rodewald, A. 1977. Nullisomy for the distal portion of Xp in a male child with a X/Y translocation. Human Genet. 39: 277-281. 